\title{
Families of Children with Down Syndrome in Turkey: A Sociocultural Approach
}

\author{
Ozlem Aydogmus Ordem ${ }^{1}$ \\ ${ }^{1}$ Assistant Professor in Sociology and Communication Sciences, Specialized in Children, Modernisation and Urban \\ Sociology, Cukurova University, Turkey \\ Correspondence: Ozlem Aydogmus Ordem, Assistant Professor in Sociology and Communication Sciences, Specialized \\ in Children, Modernisation and Urban Sociology, Cukurova University, Turkey.
}

Received: August 30, 2018

doi:10.11114/ijsss.v6i10.3579
Accepted: September 17, $2018 \quad$ Available online: September 26, 2018

URL: https://doi.org/10.11114/ijsss.v6i10.3579

\begin{abstract}
Studies on children with Down syndrome have been on the rise in recent years because interdisciplinary and multidisciplinary approaches have been developed to understand both parents and children with Down syndrome. This study aimed to analyze the views of Turkish parents of children with Down syndrome from a critical sociocultural perspective. Five families of children with Down syndrome were interviewed. These families discussed their views composed of medical and familial discourses, legal rights, bureaucracy, sociality, socialization, outsiders' perspectives, criticism to educational and medical system and resistance through social dialogue. The qualitative results of the study show that the families developed a different discourse that resisted the conventional discourses created by medical institutions and macro social structures. In addition, negative and pessimistic perspectives of others were, to a large extent, eliminated and transformed into more positive and optimistic viewpoints through social dialogue and constructive narratives.
\end{abstract}

Keywords: down syndrome, sociocultural approach, sociality, children, parents

\section{Introduction}

Studies on families of children with Down syndrome have been related to different approaches and terms. Narrative therapy, social constructivist approach, sociocultural perspective, social construction of discourses regarding disabilities, social dialogue and critical approach are among the important terms to understand families' perspectives. However, all these terms refer to transformative practices because transforming perspectives in a society is a hard and challenging task. Considering these terms, sociocultural perspective can be regarded as an umbrella term to develop a critical perspective towards conventional ideas. Sociocultural theory refers to a combination of individual, social and contextual interaction that affects and transforms social dynamics and discourses by using social dialogue and developing critical perspectives through negotiation (Falzon, 2006; Vygotsky, 1978). Social dialogue refers to challenging others and transforming addressees within an open-ended interplay because it denotes effects on others. It does not only contain mere expression of ideas but also shapes and influences others (Falzon, 2006). The idea of social dialogue was developed based on the discussions by Foucault $(1978,1979,1980,1984)$ who claimed that discourse is one of the core elements that influence individuals' lives directly because they are entrenched and molded in discourses that are not solely passive but rather that refer to formation and constitution of minds.

Sociocultural construction of children with Down syndrome has been a more profound problem than the syndrome itself in recent years (Goddard, Lehr and Lapadat, 2000; Lalvani, 2008; Van Riper, 2007) Dominance of medical and conventional discourses has affected views and perceptions of families towards children with Down syndrome substantially. However, sociocultural approaches have had a positive impact on how children with Down syndrome are perceived not only by their families but also by relatives, friends or others around them because from a sociocultural perspective, they are often taught to suffer from this syndrome and experience negative feelings (Olshansky, 1962). The first stages and reactions of families may be extremely negative (Cunnigham, 1996). In later stages, it has been often discussed that these families may undergo considerably positive transformations, although certain negative experiences such as stress or negative parenting practices (Phillips, Conners \& Curtner-Smith, 2017) are still narrated. These families have been reported to develop critical attitudes towards their experiences. Thus, it is not unusual that families 
keep both positive and negative attitudes and views simultaneously (Hsiao, 2014).

It has been a systematic discourse created and imposed through medical approaches that parenting a child with Down syndrome is a painful and completely unending burden (Lalvani, 2008). Since normality is dominantly attested, social perspectives and social construction of children with disabilities have been ignored due to medical discourses that have been traditionally prevalent (Turnbull, 1988). These families have been discursively conditioned that their views are secondary in relation to dominant discourses. However, Goddard, Lehr and Lapadat (2000) emphasize the fact that families' perspectives can be transformative and constructive in that they can generate discourses not adopted in the related literature. Deconstruction of dominant discourses that often imposes negative views and attitudes on families of children with Down syndrome (White, 1991).

In line with a sociological approach as well as social constructivist theory, this study aimed to focus on the views of the five families of children with Down syndrome by collecting data through semi-structured interviews to unravel two different discourses existing in the society that tend to normalize and marginalize or resist and develop a critical perspective towards the normalizing and marginalizing discourses through social dialogue.

\section{Method}

This study is descriptive and qualitative with rich narratives. The data were collected from five families with Down syndrome. The reason for the use of this method was that this study aimed to examine the data from a sociological and sociocultural perspective based on discourse analysis. A semi-structured interview form was prepared. However, open-ended questions were also added to elicit more detailed narratives from the families where necessary. Interview technique was adopted since inter-subjective discourses are important in qualitative studies, particularly when the subjects are marginalized in certain societies (Harstock, 1983; Smith, 1997). This standpoint epistemology assumes that socially constructed and situated viewpoints based on conventional discourses can be deconstructed by taking others' perspectives into consideration, which may provide sound objectivity (Rolin, 2009).

\subsection{Participants}

Five families of children with Down syndrome who lived in Turkey were involved in the study. The researcher did not work with children with Down syndrome professionally before. In addition, no professional training including counseling or clinical practice regarding syndromes was received. The researcher had a strong background in sociology of children and childhood. The first family had one child before the birth of the child with Down syndrome aged 9 at the time of the interview. The second family had the child with Down syndrome aged 9 before the birth of the other child. The third family had two children before the birth of the child with Down syndrome aged 6. The fourth family had only one child with Down syndrome aged 6. The fifth family had the first child with Down syndrome aged 30 before the birth of the other child. Three mothers were civil servants that had regular salaries. However, the two mothers were housewives. The second family's father was deceased, and therefore experienced financial problems although the government funds them.

Table 1. Description of family profile

\begin{tabular}{lccccc}
\hline Families & Siblings & Ages of children with DS & School Involvement & Father Involvement & Mother Involvement \\
\hline First Family & Yes & 9 & Yes & No & Yes \\
Second Family & Yes & 9 & Yes & No & Yes \\
Third Family & Yes & 6 & Yes & Yes & Yes \\
Fourth Family & No & 6 & Yes & Yes & Yes \\
Fifth Family & Yes & 30 & Graduate & No & Yes \\
\hline
\end{tabular}

\subsection{Data Collection and Analysis}

A semi-structured interview was performed to collect the data. Each interview lasted between 80 to 140 minutes. The interviews were recorded and transcribed. Field notes were also taken. The families provided detailed and rich narratives. The semi-structured interviews were composed of six elements. These elements were medical and familial discourses, legal rights, bureaucracy, sociality, socialization, outsiders' perspectives, criticism to educational and medical system and resistance through social dialogue. Each interview was visited several times to reach some commonalities as well as individual differences to be highlighted. Thus, inductive content analysis was conducted based on specific observations. Thus, open-coding was adopted in the study.

\section{Results}

The collected data from the five families provided rich and detailed descriptions of their situations and children with Down syndrome. Although each family developed and narrated their individual perspectives that varied considerably, certain commonalities were elicited from the data subsumed under five categories. 


\subsection{First Reactions: Medical and Familial Discourses}

Although a few or more years passed after the birth of their children, they state that they can remember those moments and discourses quite vividly. Besides, they define those moments and utterances as unforgettable and turning points.

F1: Until I learned that my child had a hole in her heart, I did not know that my child had this syndrome. The doctor gave me the child by showing her back but not her face. I started to cry immediately.

F3: I could not see my baby for two days because the doctor could not tell me that my son had this syndrome. He told my husband to tell me that. He could not, either. Then, the third person, a cardio surgeon, came and told me that my son had Down syndrome. I could not help crying for hours. I asked my own doctor about why he could not tell me. He said that he could not dare to say it. I could not get out of this shock for months because it was something I did not know of at all.

F5: I experienced an abortion before because my baby was going to be disabled. Also, some of my family members had some disabled children. Therefore, I was familiar with and prepared for any situation. When they told me that I would have a child with Down syndrome, I was again happy. I started to buy books about this syndrome and to learn a lot of things to teach her. She is 30 years old now and working as a civil servant.

The narratives of the families except for the fifth family indicate that the first reactions were composed of shock, cries and hopelessness as well as sadness because the discourses produced around the families in the hospitals were totally negative because they reported that they had not even heard what the syndrome meant. Therefore, additional reactions of the medical experts around them influenced their perspectives and perceptions negatively. The fifth family was both knowledgeable and prepared for this syndrome. Besides, this family never complained about the situation. Rather, they felt extremely ecstatic and excited to have a child.

\subsection{Legal Rights and Bureaucracy}

All the families gained considerable awareness of their legal rights and reported the problems about bureaucracy. All of them stated that they made great efforts to solve the problems in bureaucracy.

F3: We have learned a lot about our rights since our child was born. We made use of them. However, although legally we have a lot of rights, we face serious problems in bureaucracy such as receiving permission from the institution I am working at.

F4: After I became the member of Association of Down Syndrome in Turkey, I started to learn more about my rights.

F5: I am aware of all my rights. I wrote to the presidency, prime minister and all other related ministries to go after my rights. I know that one needs to make very great efforts to claim rights. I really got what the rights entailed. Now my child is working as a civil servant thanks to my and my husband's efforts. My child also knows her rights partially. She shares her problems with us in the evenings.

All of the families had little information about their rights and encountered serious bureaucratic problems. In principle, the laws were passed and issued. However, in practice their problems were hardly noticed. Knowing and being aware of the rights were the first step to act in everyday life. However, practical steps were partially taken, which at times hardened families' lives.

\subsection{Sociality and Socialization}

Sociality and socialization were another two most frequently terms that the families used because they emphasized the fact that almost all families with Down syndrome or other syndrome need social events and activities because socialization are one of the most effective way to learn from each other. In addition, they noted that these people can establish better empathy and rapport with each other and that since there is still a long way for their society to be more aware of this issue, social acceptance and lack of social rejection come as facilitators for them.

F1: We join some activities that we can do together at two or three different rehabilitation centers. In addition, we use social media very effectively. When we have something to share, we do it through social media. We also take our children to the classes or courses that the local council organizes.

F2: My daughter is 9 years old and has swimming, dancing and gym awards. I am totally alone and lonely. Therefore, there is only one way left for my daughter to develop her sports, academic and social activities. It is really sociality. I, as a mother, spend most of my time searching for social activities. I also established a website called 'Down syndrome Fraternity' with some of my friends. We socialize thanks to this website where we have 17.000 members.

F3: We often try to keep our child busy. We often look for social activities. Each day we are trying to be busy with some activities such as drawing and dancing. He wants to play all the time with no sign of tiredness.

The families insistently emphasized the importance of sociality and socialization. They perceived sociality as a very 
effective means to understand each other and to develop constructive and transformative discourses that acted, in a way, as a narrative therapy. The importance of sociocultural perspective can be seen in this category because the families endeavored to reconstruct perception and constructs given to them by the society there were in. They used social dialogue very effectively among each other.

\subsection{Outsiders' Perspectives}

Outsiders' perspective refers to anyone outside the family of the child with Down syndrome. Outsiders can be doctors, nurses, teachers or people in a spontaneous social or physical setting. The families cared for others' perspectives a lot because they believe that it is also others that construct normality and abnormality. Therefore, it can be said that they are sensitive to others' perspectives because intimacy, rapport, empathy, sympathy, social support and social dialogue are considerably reduced when outsiders encounter their children.

F1: It is clear that most people in the street are unaware of this syndrome. They do not have enough information about this issue. Therefore, they think that we are trouble-makers in the society. This perspective drives us to feel secluded from the society. In addition, they approach us as if my child is totally mentally retarded. They do not that these children can work or learn various skills and even get married.

F3: What I often feel is this. They pity on us. They do not know that my child has this syndrome, and I say: Do not be scared. She will do no harm to you.

F4. The people around us look at us with pity. They make us feel that you are already overwhelmed. Some people also behave impatiently when we walk or visit a place.

Since this syndrome has not been widespread in the society, some people exhibited negative behaviors towards both the families and the children. Therefore, it remains very vital to transform perceptions, taken-for-granted constructs and perceptions of the society. Raising awareness and teaching to use the right term for these families and children seem to be a critical step in changing conventional discourses.

\subsection{Criticism to Educational and Medical System}

Educational and medical systems were criticized by the families because they had difficulty accessing some facilities, and the infrastructure of these institutions was insufficient to help both the families and these children. They state that children with Down syndrome are faced with serious health risks from heart problems to speech problems. Therefore, they need broader accessibility to facilities. Another problem that they encounter is that schools do not have professional educators or teachers because in Turkey there are only a few universities that provide special education about these children. In addition, Turkey has a few academics that have a strong background in special education. Therefore, the families stress the fact that access to medicine and receiving special education from professional teachers may seem unlikely at certain times.

F2: Rehabilitation centers are extremely inadequate. They learn through trial and error. In addition, there are not enough books that can teach us a lot of things. We also want our child to go to both regular schools and rehabilitation centers.

F3: I cannot find a professional speech therapist. I have been looking for a speech therapist for 4 years. I could not find them. Another problem is that some teachers are graduates of high schools. We know this issue.

F5: We and teachers learn by ear. There seem a lot of schools in my hometown. However, most of them do not have enough number of teachers or are closed. They cannot find or hire professional teachers. There are only a few speech therapy departments in Turkey. I think that it will take a long time to find professional teachers.

The most severe criticisms were directed towards hospitals and schools because their perspectives and discourses seemed to have affected them negatively. In addition, insufficient qualifications of the staff in the schools and rehabilitation centers shattered their trust in these institutions. Another common problem in all the families was the absence of the professionally educated speech therapists.

\subsection{Resistance through Social Dialogue}

Social dialogue is one of the key terms in this study (Falzon, 2006) because social dialogue entails resistance and transforming others. It seems that the families endeavored to use social dialogue very effectively. Thus, some institutions had to question themselves and their perspectives as well as their weaknesses. Although the families encountered serious problems at different levels, they were able to resist and become immune to certain problems. It can be interpreted that these families developed educational institutions and centers positively thanks to developing critical approaches. They used social dialogue as an effective tool to access better educational facilities (Falzon, 2006). By improving sociality and socialization with the families of children with Down syndrome, they have reported that they have learnt a lot from each other. It can be said that considerable transformation has been experienced. The fifth family was extremely positive and optimistic about their child and defined their life as very busy, social, optimistic and helpful. 


\section{Discussion}

The results of the study show that the families experienced certain difficulties owing to the lack of accessibility to certain facilities. However, they established rapport and strong social relations with other families of children with Down syndrome. Four of the families noted that they had serious shock at the beginning of the process. However, in time they accepted the situation by learning from different sources and establishing social dialogue with others because social dialogue entails questioning and authentic speaking with others (Falzon, 2006).

One of the most negative factors that affected them was the medical discourse that emphasized the disability, impairment, disorder or handicap. Medical perspective influenced the families' perspective negatively since these doctors and nurses have standard views that contain abnormality of these children with Down syndrome. Thus, it can be said that one of the institutions that causes abnormality to spread in the society is medical institution. Another serious problem that was encountered was that lack of information and awareness was present in the society. Outsiders' perspectives caused confusion and stress in them since they felt that they were, to some extent, marginalized. The families emphasized that correcting misunderstandings of others was more tiring than taking their children to different activities because they found themselves explaining the situation of their children. This study underscores the importance of raising awareness in the society and informing individuals starting at early ages. Goddard, Lehr and Lapadat (2000) note the fact that individual stories that function as narrative therapies for families are formed within broader cultural and social discourses (Lalvani, 2008; Turnbull, 1988; White, 1991; Zimmerman \& Dickerson, 1996). The families in this study as well formed strong social relationships with the families of the children with Down syndrome. Davis (1997) stresses the fact that certain norms are created in the society, which causes the disabled to be otherized because it is social discourses that constitute this perception in the society. Similarly, Lalvani (2008) showed that transformations were experienced in the process of perceiving the society by the families of children with Down syndrome. Kleiwer (1998) also notes that discourses are socially constructed realities. The issue of Down syndrome has also been socially constructed. Therefore, there is always a chance to change the perceptions of others that see normalcy as conventional. Thus, transformation of individuals 'minds through social dialogue can become a pivotal issue because normalcy that is socially constructed can be reversed again through social dialogue. The initial disappointments influenced by the dominant discourses that, to some extent, constructed their realities and perceptions turned into positive accounts. Some mothers were concerned that social consequences of having children with Down syndrome could be negative, unpredictable, hard and complex (Lalvani, 1997;Morton and Gibson, 2003). However, in time they started to develop more optimistic perspectives via constructive feedback that they received from each other.

The families show reaction when they are described as families that suffer, lead hard lives or have heavy burdens on them. Rather, they prefer to be perceived as a part of the society (Goddard, Lehr and Lapadat, 2000; Morton and Gibson, 2003). They are aware that normalcy is attested by medical and macro social discourses. The families are observed to resist these discourses and develop a critical approach owing to the normalizing discourses that they encounter in the society. Thus, it can be interpreted that they have their own personal constructs and construal of life (Kelly, 1977; Olssen, 1996. The stories that they told during the interviews contained optimism and positive ideas. Thus, it seems that there are two different versions of the same tale. One is negative and pessimistic under the effect of medical and conventional discourses, while the other is positive and optimistic based on individual narratives that resist the discourses of the former and provide rapport and strong relations between each other (Ferguson \& Ferguson, 1995).

\section{Limitations of the Study}

The study has several limitations. First, the sample size was composed of only five families. Second, only convenience sampling was used. The families were homogenous in that they were all Turkish and had almost similar income except for one family whose father was deceased and that was funded by the government only. Other ethnic groups could not be included into the study. All the parents in the study held at least BA degrees, which may have affected their comments in terms of gaining awareness of the issues that might be negative for them. Another limitation is that only two fathers were able to be involved in the study. The findings of this study cannot be generalized taking the limitations above into consideration. Future studies may include different families from different ethnicities and backgrounds to have more generalizable data.

\section{Conclusion}

This study aimed to unearth the views of the families of the children with Down syndrome. The results in general show that the discourses of the families oppose the discourses of medical institutions and macro social structures. The concept and content of Down syndrome seem to be under the impact of the society' normalizing discourses. Therefore, this syndrome contains its own cultural and social values and constructions around the term of normalcy. However, the families resisted almost every kind of hard step placed before them at legal, medical, social, educational or cultural levels. They developed critical approaches towards the system imposed on them through discourses and concrete practices. 
Several recommendations can be voiced. Experts and practitioners in medicine and education need to reassess their views about normalcy in the society and to develop critical perspectives towards conventional terms used about children with Down syndromes and their families. They should also take families' perspectives into consideration more seriously. Experts in law should supervise whether law is enforced or not to facilitate the lives of families of children with Down syndrome. Understanding these people starts by raising awareness in the society. Various institutions and these families can gather to create critical and novel discourses that have historically, socially and culturally been in severe pursuit of normalizing and marginalizing individuals in the society.

\section{References}

Abbott, D. A., \& Meredith, H. M. (1986). Strengths of parents with retarded children. Family Relations, 35, 371-375. https://doi.org/10.2307/584363

Cunningham, C. (1996). Families of children with Down syndrome. Down Syndrome Research and Practice, 4(3), 87-95. https://doi.org/10.3104/perspectives.66

Davis, L. J. (1997). Constructing normalcy. In L.Davis (Ed.), The disability studies reader (pp. 9-28). New York: Routledge.

Falzon, C. (2006). Foucault and social dialogue: Beyond fragmentation. Routledge: London.

Ferguson, P. M., \& Ferguson, D. L. (1995). The interpretivist view of special education and disability: The value of telling stories. In T. Skrtic (Ed.), Disability and democracy : Reconstructing (special) education for postmodernity (pp. 104-121). New York: Teachers College Press.

Foucault, M. (1978). The History of Sexuality: An Introduction.Ttrans. Robert Hurley, Harmondsworth: Penguin.

Foucault, M. (1979). Governmentality. Trans. Rosi Braidotti. Ideology and Consciousness, 6, 5-21.

Foucault, M. (1980). Body/Power. Ttrans. Colin Gordon, in Colin Gordon (ed.), Power/Knowledge: Selected Interviews and Other Writings 1972-1977 by Michel Foucault, New York: Pantheon

Foucault, M. (1984). Nietzsche, Genealogy, History.Ttrans. Donald Bouchard and Sherry Simon, in Paul Rabinow (ed.). The Foucault Reader, New York: Pantheon.

Goddard, J. A., Lehr, R., \& Lapadat, J. C. (2000). Parents of children with disabilities: Telling a different story. Canadian Journal of Counselling and Psychotherapy/Revue canadienne de counseling et de psychothérapie, 34(4).

Hartsock, N. C. (1983). The feminist standpoint: Developing the ground for a specifically feminist historical materialism. In Discovering reality (pp. 283-310). Springer, Dordrecht.

Hsiao, C. Y. (2014). Family demands, social support and family functioning in Taiwanese families rearing children with D own syndrome. Journal of Intellectual Disability Research, 58(6), 549-559. https://doi.org/10.1111/jir.12052

Kelly, G. A. (1977). Personal construct theory and the psychotherapeutic interview. Cognitive therapy and research, 1(4), 355-362. https://doi.org/10.1007/BF01663999

Kleiwer, C. (1998). Schooling children with Down syndrome: Toward an understanding of possibility. New York: Teachers College Press.

Lalvani, P. (2008). Mothers of children with Down syndrome: Constructing the sociocultural meaning of disability. Intellectual and developmental disabilities, 46(6), 436-445. https://doi.org/10.1352/2008.46:436-445

Morton, M., \& Gibson, P. (2003). The rhetoric and practice of partnership: Experiences in the context of disability. Paper presented at Connecting Policy Research and Practice: The Social Policy Research and Evaluation Conference, Ministry of Social Development, Wellington Convention Center, Wellington, New Zealand.

Olshansky, S. (1962). Chronic sorrow. A response to having a mentally defective child. Social Casework, 43, 190-193. https://doi.org/10.1177/104438946204300404

Olssen, M. (1996). Radical constructivism and its failings: Anti-realism and individualism. British Journal of Educational Studies, 44(3), 275-295. https://doi.org/10.1080/00071005.1996.9974075

Phillips, B. A., Conners, F., \& Curtner-Smith, M. E. (2017). Parenting children with down syndrome: An analysis of parenting styles, parenting dimensions, and parental stress. Research in developmental disabilities, 68, 9-19. https://doi.org/10.1016/j.ridd.2017.06.010

Rolin, K. (2009). Standpoint theory as a methodology for the study of power relations. Hypatia, 24(4), 218-226. https://doi.org/10.1111/j.1527-2001.2009.01070.x

Smith, D. E. (1997). Comment on Hekman's" Truth and Method: Feminist Standpoint Theory Revisited". Signs: Journal 
of Women in Culture and Society, 22(2), 392-398. https://doi.org/10.1086/495164

Taylor, S. J. (2000). "You're not a retard, you're just wise:” Disability, social identity and family networks.Journal of Contemporary Ethnography, 29, 58-92. https://doi.org/10.1177/089124100129023828

Turnbull, A. P. (1988). The challenge of providing comprehensive support to families. Education and Training in Mental Retardation, 23, 261-272.

Van Riper, M. (2007). Families of children with Down syndrome: responding to "a change in plans" with resilience. Journal of pediatric nursing, 22(2), 116-128. https://doi.org/10.1016/j.pedn.2006.07.004

Vygotsky, L. S. (1978). Mind in Society: The Development of Higher Psychological Processes. M. Cole, V. John-Steiner, S. Scribner, \& E. Souberman (Eds.). Cambridge, MA: Harvard University Press.

White, M. (1991). Deconsttuction and therapy. Dulwich Centre Newsletter, 3, 1-2.

Zimmerman, J. L., \& Dickerson,V. C. (1996). If problems talked: Narrative therapy in action. New York: The Guilford Press.

\section{Copyrights}

Copyright for this article is retained by the author(s), with first publication rights granted to the journal.

This is an open-access article distributed under the terms and conditions of the Creative Commons Attribution license which permits unrestricted use, distribution, and reproduction in any medium, provided the original work is properly cited. 